\title{
Analysis of Rupture Directivity for the 2004 Sumatra Earthquake from the Rayleigh-Wave Phase Velocity
}

\author{
Jo-Pan Chang ${ }^{1,2}$, Ruey-Der Hwang ${ }^{2,}$, Chien-Ying Wang ${ }^{1}$, Guey-Kuen $\mathrm{Yu}^{3}$, \\ Wen-Yen Chang ${ }^{4}$, and Tzu-Wei Lin ${ }^{5}$ \\ ${ }^{1}$ Institute of Geophysics, National Central University, Jhongli 320, Taiwan, ROC \\ ${ }^{2}$ Department of Geology, Chinese Culture University, Taipei 111, Taiwan, ROC \\ ${ }^{3}$ Department of Civil Engineering, Vanung University, Jhongli 320, Taiwan, ROC \\ ${ }^{4}$ Department of Natural Sciences, National Science Council, Taipei 106, Taiwan, ROC \\ ${ }^{5}$ Seismology Center, Central Weather Bureau, Taipei 100, Taiwan, ROC
}

Received 25 November 2008, accepted 27 March 2009

\begin{abstract}
The rupture directivity for the 2004 Sumatra earthquake is analyzed by examining differences between the phase-delay times of Rayleigh-waves (in the 140 - $160 \mathrm{sec}$ period range) arising from the main shock and reference earthquakes. A long source-process time $(\sim 463.0 \mathrm{sec})$ and large rupture length $(\sim 1164.0 \mathrm{~km})$ are derived from this analysis of rupture directivity. The source-process time for this earthquake is larger than for either the 1960 Chile or 1964 Alaska earthquakes. This might be due to the length of the rupture that occurred during earthquake faulting. The estimated rise time for the 2004 Sumatra earthquake, $92.0 \mathrm{sec}$, is approximately $20 \%$ of the whole source duration and also larger than those for the 1960 Chile and 1964 Alaska earthquakes. This likely reflects a fundamental difference between the frictional properties of these earthquakes. When the rise time is taken into account, an estimated rupture velocity of approximately $3.1 \mathrm{~km} \mathrm{sec}^{-1}$ is obtained. This value is higher than that found in previous studies carried out on the basis of hydroacoustic data and regional seismic networks. In this study, we obtain additional evidence from analysis of the surface-wave phase-delay time which confirms the basic features of the rupturing of the 2004 Sumatra earthquake. The results can also provide some constraints for the study of source rupturing for this earthquake.
\end{abstract}

Key words: Phase-delay time, Rayleigh-waves, Rupture length, Rupture velocity, Rise time

Citation: Chang, J. P., R. D. Hwang, C. Y. Wang, G. K. Yu, W. Y. Chang, and T. W. Lin, 2010: Analysis of rupture directivity for the 2004 Sumatra earthquake from the rayleigh-wave phase velocity. Terr. Atmos. Ocean. Sci., 21, 243-251, doi: 10.3319/TAO.2009.03.27.01(T)

\section{INTRODUCTION}

On 26 December 2004, a large earthquake $\left(\mathrm{M}_{\mathrm{w}}=9.0\right.$ 9.3) triggered a destructive tsunami and large rupturing between the Sunda and India-Australian plates. The $2004 \mathrm{Su}-$ matra earthquake's (cf. Lay et al. 2005) rupture length and source-process time were first reported to be hundreds of kilometers long with a $\sim 200$ - $400 \mathrm{sec}$ slip distribution inverted from teleseismic $P$-waves (Yagi 2005; Yamanaka 2005). Recently, studies of high-frequency energy radiation from $P$-waves, as well as hydroacoustic data have confirmed the rupture length to be $1100-1300 \mathrm{~km}$ (Guilbert et al. 2005; Ishii et al. 2005; Krüger and Ohrnberger 2005; Lomax 2005;

\footnotetext{
* Corresponding author

E-mail:hrd@faculty.pccu.edu.tw
}

$\mathrm{Ni}$ et al. 2005). The source-process time is $430-515 \mathrm{sec}$, with an average estimated rupture velocity from 2.3 to $2.8 \mathrm{~km} \mathrm{sec}^{-1}$ (Guilbert et al. 2005; Ishii et al. 2005; Krüger and Ohrnberger 2005; Lomax 2005; Ni et al. 2005). Ammon et al. (2005) derived the slip distribution on the fault plane from the deconvolution of surface waves. They found the largest slip to be located along a $600-\mathrm{km}$-long portion of the rupture zone caused by the main shock. Others found the rupture velocity for the earlier part of the earthquake rupture to be faster $\left(2.4-4.1 \mathrm{~km} \mathrm{sec}^{-1}\right)$ than that of the later one (1.5 - $2.3 \mathrm{~km} \mathrm{sec}^{-1}$ ) (de Groot-Hedlin 2005; Guilbert et al. 2005; Krüger and Ohrnberger 2005; Tsai et al. 2005; Vigny et al. 2005). Seno and Hirata (2007) proposed a rupture model, in which the rupture velocity $\left(2.5 \mathrm{~km} \mathrm{sec}^{-1}\right)$ at depth is rapid while the rupture velocity $\left(0.7 \mathrm{~km} \mathrm{sec}^{-1}\right)$ 
seaward is slow. This is interpreted to be a possible tsunami source. However, based on multiple event analysis, Tsai et al. (2005) found an average apparent rupture velocity of $\sim 3.0 \mathrm{~km} \mathrm{sec}^{-1}$.

Variations in seismic-wave-duration from the station azimuth are commonly observed following a large earthquake because of the large faulting and extending. This phenomenon is generally called rupture directivity (BenMenahem 1961). Ben-Menahem (1961) first proposed the finite moving source theory to account for the effect of rupture propagation on far-field seismograms. Basically, source finiteness would result in a time delay in wave propagation, and weaken the amplitude of the seismic waves, which show up as a number of nodes in the Fourier spectra (BenMenahem 1961; Aki and Richards 1980). There are many methods for the rupture directivity analysis of large earthquakes, including deconvolution of $P$-waves or surfacewaves, analysis of high-frequency $P$-wave radiation, and so on (Schwartz and Ruff 1985; Ammon et al. 2005; Ni et al. 2005). Hwang et al. (2001) used phase-delay time differences of Rayleigh waves between the main shock and its two large aftershocks to derive the rupture directivity and determine the fault parameters for the 1999 Chi-Chi earthquake.

In this study, we provide additional evidence to confirm the rupture directivity and source-process time for the 2004 Sumatra earthquake. We use differences in the phase-delay time of Rayleigh-waves between the main shock and reference earthquakes close to the main shock (cf. Hwang et al. 2001). The advantage of this method is that one can efficiently and rapidly estimate the rupture directivity and source-process time for large earthquakes, which then might provide additional constraints for use in other studies, such as source rupture analysis.

\section{DATA AND ANALYSIS}

In this study, we extract long-period Rayleigh waves from vertical-component seismograms provided by the IRIS Data Management Center. These are then used to investigate the rupture directivity and source-process time of the 2004 Sumatra earthquake. In our analysis, only data with good surface-wave energy excitation and with epicentral distances from $30^{\circ}$ to $90^{\circ}$ were used to perform phase-velocity measurement along the great-circle path. The instrumental response was first removed from each seismogram. The seismograms were also filtered, between $0.001-0.1 \mathrm{~Hz}$ for the main shock and $0.004-0.1 \mathrm{~Hz}$ for the rest. Table 1 shows the source parameters of these events as reported from the Harvard CMT catalog.

The phase-delay time was first calculated using the single-station method. The phase velocity of surface-waves along the great-circle path from earthquake to station was derived (cf. Hwang 1999; Chang et al. 2007). The phasevelocity was subsequently converted into the phase-delay time. The phase-delay time of the surface wave to a given station at period $T$ can be written as

$t(T)=\frac{L}{C(T)}=\left[\phi_{S R}(T)-\phi_{0 R}(T) \pm N\right] T$

where $C(T)$ and $t(T)$ denote the phase-velocity and the corresponding travel time (phase-delay time) of a surface wave at a given period $T ; L$ is the epicentral distance; $\phi_{S R}(T)$ is the station phase after removing the instrumental response; $\phi_{0 R}(T)$ is the initial phase of the source calculated from a known focal mechanism and the velocity structure of the source area (cf. Wang 1981); $N$ is an arbitrary integer for detecting the reasonable phase-velocities in the longperiod part.

The problem of the $2 \pi$-phase ( $N$-value) giving rise to an obscure determination of the phase-velocity means that we must modulate the $N$-value in Eq. (1) so as to detect a reasonable phase-velocity. The differences of phase-velocity arising from the various $N$-values are larger for the long-period parts than for the short-period parts (see Fig. 1). The reason is that the long-period signal is relatively less subject to interference by the $2 \pi$-phase part. Hence, the phase-velocity at the long-period part can be used as a basis for determining a reasonable dispersion curve. The phase-velocity is estimated using a global average Earth velocity model, such as PREM or the iasp91 model. It is estimated to be about $4.0 \mathrm{~km} \mathrm{sec}^{-1}$

Table 1. Source parameters used in this study.

\begin{tabular}{|c|c|c|c|c|c|c|c|c|c|c|c|c|}
\hline \multirow{2}{*}{ No. } & \multirow{2}{*}{ Date } & \multicolumn{3}{|c|}{ Origin Time (UT) } & \multirow{2}{*}{\multicolumn{2}{|c|}{ Location }} & \multirow{2}{*}{$\begin{array}{c}\text { Depth } \\
(\mathbf{k m})\end{array}$} & \multirow{2}{*}{$\begin{array}{l}\text { H.D. } \\
\text { (sec) }\end{array}$} & \multirow{2}{*}{$\mathbf{M}_{\mathbf{w}}$} & \multicolumn{3}{|c|}{ Fault Plane Solution } \\
\hline & & hr. & $\min$. & sec & & & & & & Strike & dip & slip \\
\hline 1 & $2002 / 11 / 02$ & 01 & 26 & 10.7 & $96.08^{\circ} \mathrm{E}$ & $2.82^{\circ} \mathrm{N}$ & 30 & 12.4 & 7.2 & $297^{\circ}$ & $16^{\circ}$ & $73^{\circ}$ \\
\hline 2 & $2002 / 11 / 02$ & 09 & 46 & 46.7 & $96.39^{\circ} \mathrm{E}$ & $2.95^{\circ} \mathrm{N}$ & 27 & 3.3 & 6.3 & $303^{\circ}$ & $13^{\circ}$ & $56^{\circ}$ \\
\hline 3 & $2004 / 12 / 26$ & 00 & 58 & 53.5 & $95.98^{\circ} \mathrm{E}$ & $3.30^{\circ} \mathrm{N}$ & 30 & - & 9.0 & $327^{\circ}$ & $6^{\circ}$ & $105^{\circ}$ \\
\hline 4 & $2005 / 02 / 26$ & 12 & 56 & 58.3 & $95.38^{\circ} \mathrm{E}$ & $2.84^{\circ} \mathrm{N}$ & 12 & 6.3 & 6.7 & $297^{\circ}$ & $6^{\circ}$ & $72^{\circ}$ \\
\hline
\end{tabular}

*Source parameters are provided from the Harvard CMT catalog. Event 3 is the 2004 great Sumatra earthquake. H.D. = source half-duration. 

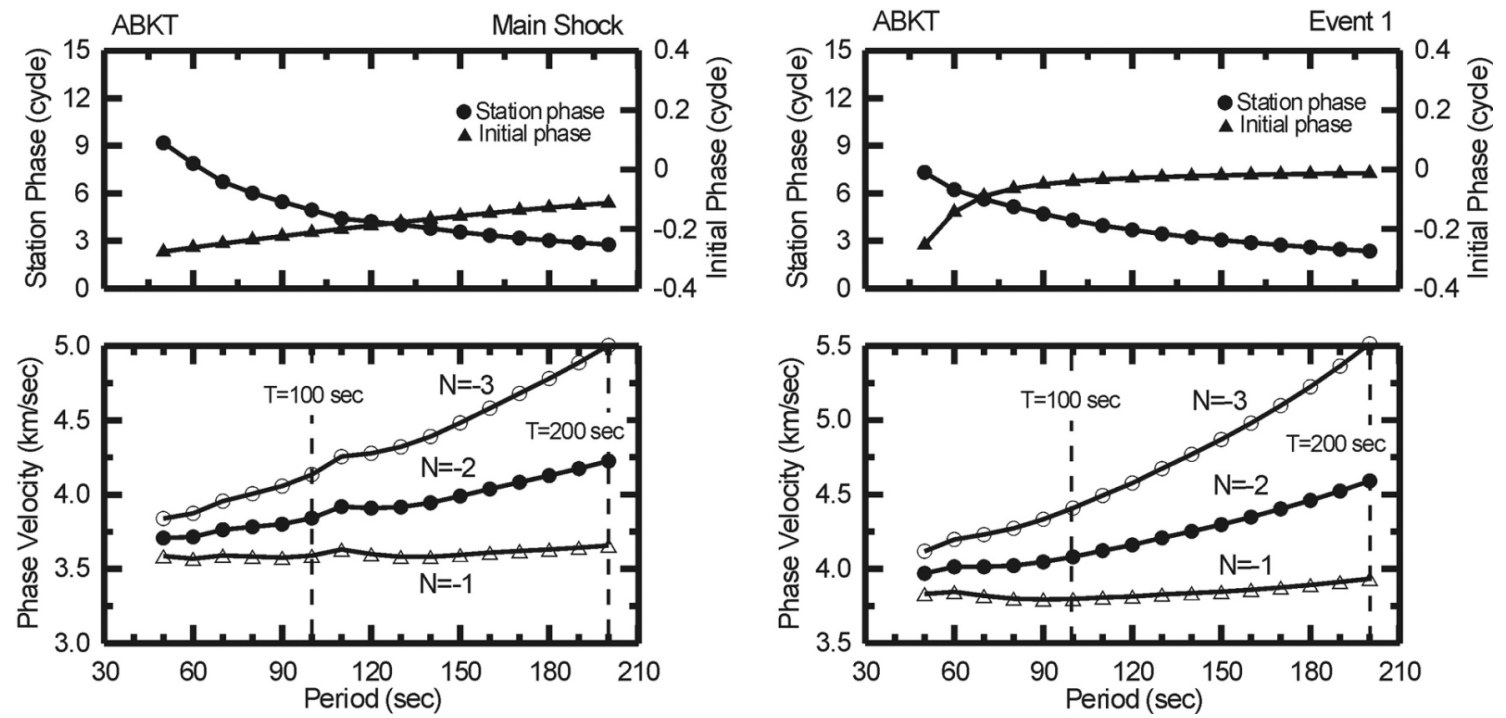

Fig. 1. The upper panels denote the station phase observations (solid circles) and source phase observations (solid triangles) of the main shock and event 1 (see Table 1) at station ABKT (located at $37.9304^{\circ} \mathrm{N}$ and $58.1189^{\circ} \mathrm{E}$ ). These phases are represented in fractions of a circle, i.e., the real phase (in radian) divided by $2 \pi$. The lower panels show the phase velocities determined using various $N$-values. By selecting a correct $N$-value, we can obtain a reasonable dispersion curve for the phase-velocity as shown by the solid circle in the lower panels.

for the 100 -s period and about $4.5 \mathrm{~km} \mathrm{sec}^{-1}$ for the 200 -s period, neglecting the effect of a finite source on the phasevelocity calculation. These are usually taken as indicators to judge whether the dispersion curve indicates reasonable values.

Figure 1 shows an example of phase-velocity measurements from station ABKT for the main shock, and event 1 (see Table 1). Apparently, an incorrect $N$-value leads to an unreasonable phase-velocity for both the main shock and event 1 . When $N=-2$, the phase velocity for event 1 is $4.08 \mathrm{~km} \mathrm{sec}^{-1}$ for $100 \mathrm{sec}$ and $4.59 \mathrm{~km} \mathrm{sec}^{-1}$ for $200 \mathrm{sec}$. These values are in agreement with the general values. When $N=-1$ and $N=-3$, the values are 3.80 and $4.41 \mathrm{~km} \mathrm{sec}^{-1}$ for $100 \mathrm{sec}$, and 3.93 and $5.51 \mathrm{~km} \mathrm{sec}^{-1}$ for $200 \mathrm{sec}$, somewhat different from the general ones. For the main shock, the phase-velocity is $3.84 \mathrm{~km} \mathrm{sec}^{-1}$ for $100 \mathrm{sec}$ and $4.22 \mathrm{~km} \mathrm{sec}^{-1}$ for $200 \sec$ when $N=-2$; however, for $N=-1$ and $N=-3$, the values are 3.59 and $4.14 \mathrm{~km} \mathrm{sec}^{-1}$ for $100 \mathrm{sec}$, and 3.66 and $5.00 \mathrm{~km} \mathrm{sec}^{-1}$ for $200 \mathrm{sec}$, quite different from the general values. Obviously, for the main shock, the rupture directivity produces a lower apparent phase-velocity $\left(3.84 \mathrm{~km} \mathrm{sec}^{-1}\right.$ at $100 \mathrm{sec}$ and $4.22 \mathrm{~km} \mathrm{sec}^{-1}$ at $200 \mathrm{sec}$ ) in comparison to an ordinary phase-velocity. Figure $2 \mathrm{a}$ shows the distribution of the stations, and the locations of the 2004 Sumatra earthquake and three reference earthquakes close to the main shock. Included also in Fig. 2a are fault plane solutions for the events used (Table 1). Figure $2 \mathrm{~b}$ displays Rayleigh waves recorded at stations MAJO and ABKT for the main shock and event 1 (see Table 1); Figure 2c shows the corresponding phase-delay times of Rayleigh waves at periods of $100-200 \mathrm{sec}$ as derived from Eq. (1).
The time it takes for surface-waves to propagate from source to station includes two phase-delay times: one is from the source and is due to the rupture directivity and initial phase; the other is from the path effect due to propagation from the source through the earth's structure to the station. In order to extract information about the source from seismograms, we must first eliminate the path effect. Seismograms generated during the main shock and reference earthquakes have basically the same propagation path. This means that differences in travel-time between the main and reference earthquakes have removed the path effect. Figure $2 \mathrm{c}$ also shows differences in the phase-delay time of Rayleighwaves between the main shock and event 1 observed at MAJO (about 150 -s at the 150 -s period). They are obviously different from those observed at ABKT (about 90-s at the 150 -s period). The differences in phase-delay time for MAJO and ABKT observations indicate the source duration, that is, the source duration varies with the observation station (i.e., azimuth). Hence, the directivity of rupturing of a great earthquake is observable from such analysis.

Owing to inconsistencies in location (epicenter and source depth) and focal mechanism between the main shock and the reference earthquakes, corrections must be made before the observed source duration can be determined for each station. First, the travel time of the surface-wave, which is affected by the source depth and focal mechanism, can be corrected through Eq. (1). Then, the source duration $T_{S P T}^{o b s}$ observed at a given station can be determined [Hwang et al. 2001; please also refer to Eqs. (5) and (6) in the next section]:

$T_{S P T}^{o b s}=2\left(t_{m}-t_{a}\right)+2\left[\left(d_{a}-d_{m}\right) / C\right]+S_{a}$ 


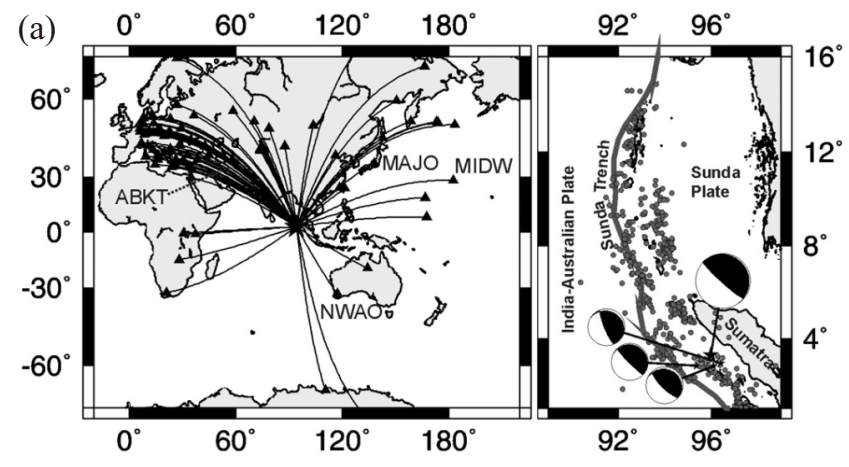

(b) MAJO, $A Z=44.0^{\circ}$

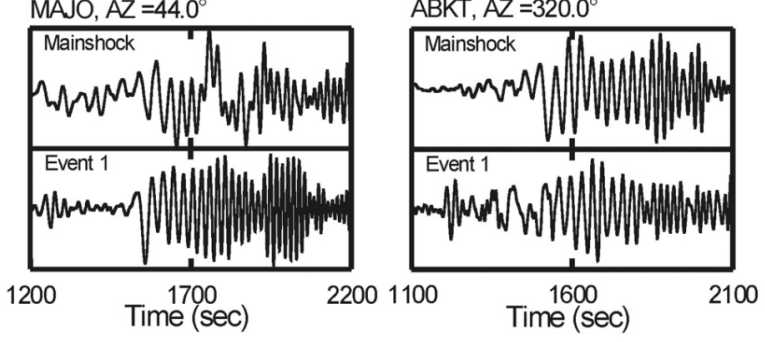

(c)
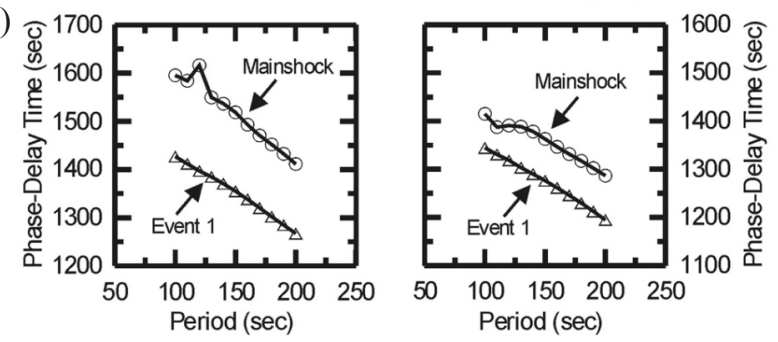

Fig. 2. (a) Station coverage around the 2004 Sumatra earthquake and the focal mechanisms of the main shock and reference earthquakes as reported in the Harvard CMT catalog. The stars and triangles denote the events and stations, respectively. Aftershocks of $\mathrm{M} \geq 5.0$ are indicated by solid circles; (b) Rayleigh waves observed at stations MAJO (located at $36.5425^{\circ} \mathrm{N}$ and $138.2073^{\circ} \mathrm{E}$ ) and $\mathrm{ABKT}$ from the main shock and event 1 ; (c) phase-delay times for periods of $100-200 \mathrm{sec}$ at stations MAJO and ABKT calculated for the main shock and event 1.

where $t_{m}$ and $t_{a}$ are the phase-delay times of the surfacewaves from the main shock and reference earthquake, respectively; $d_{m}$ and $d_{a}$ are the epicentral distances for the main shock and reference earthquake; $C$ is the phase velocity in the source area; $S_{a}$ is the average source duration of the reference earthquake on which the effect of the finite source is neglected. The middle term on the right side of Eq. (2) is designed to correct the time difference due to the different locations of the main shock and reference earthquake. The last term in Eq. (2) is a correction of the phasedelay time from the source duration of the reference earthquake. After detailed analysis of the phase-delay time we obtain a total of 132 data points exhibiting the source-duration with varying azimuth (see Fig. 3a).

\section{RUPTURE DIRECTIVITY ANALYSIS}

The Fourier amplitude and phase velocity of the surface waves are simultaneously affected by the source time function and fault finiteness (cf. Aki and Richards 1980). Assuming the source time function to have a homogeneous rise time $(\tau)$, the Fourier transform $[S(\omega)]$ can be written as

$S(\omega)=\left|\frac{\sin \left(\frac{\omega \tau}{2}\right)}{\frac{\omega \tau}{2}}\right| e^{-j \frac{\omega \tau}{2}}$

where $\omega$ is the angular frequency. The rise time is not connected with the observed azimuth.

For a unilateral faulting event, the fault finiteness function in the frequency-domain can be expressed as follows (Ben-Menahem 1961):

$F(\omega, \Theta)=\left|\frac{\sin X}{X}\right| e^{-j X}$

where $X=\frac{\omega}{2}\left(\frac{L}{V_{r}}-\frac{L}{C} \cos \Theta\right)$, related to $\omega$ and the observed azimuth; $L$ and $V_{r}$ are the rupture length and rupture velocity, respectively; $C$ is the phase velocity in the source region and is a function of $\omega ; \Theta=\phi_{s}-\phi_{f}$ is the difference between the station azimuth $\left(\phi_{s}\right)$ and the direction of the fault rupturing $\left(\phi_{f}\right)$.

Equation (4) can be used assuming that the earthquake faulting is a uniform rupture process, including a uniform rupture direction, rupture velocity and slip velocity. In other words, Eq. (4) does not take account of whether larger energy releases occur during faulting or not. It cannot be used to interpret the complexity of the earthquake rupture, but mainly accounts for the first-order rupture characteristic of large earthquakes. Equation (4) has been successfully applied to several historical earthquakes such as the 1960 Chile and the 1964 Alaska earthquakes (Press et al. 1961; BenMenahem et al. 1972).

Phase terms from both the source rise time $\left[e^{-j \frac{\omega \tau}{2}}\right.$ in Eq. (3)] and fault finiteness $\left[\mathrm{e}^{-j X}\right.$ in Eq. (4)] give the phase delay of the surface-wave propagation. In other words, the phase velocity is apparently slower than that determined when neglecting fault finiteness. For an earthquake with unilateral faulting, the phase-delay time $\left(t_{\text {delay }}\right)$ resulting from the source rise time and fault finiteness can be written as

$t_{\text {delay }}=\frac{\arg [S(\omega)]}{\omega}+\frac{X}{\omega}=\frac{\tau}{2}+\frac{1}{2}\left(\frac{L}{V_{r}}-\frac{L}{C} \cos \Theta\right)$

The source-process time $\left(T_{S P T}\right)$ observed at a given station is 2 times the length of $t_{\text {delay }}$, and can be expressed in the 
following form:

$$
T_{S P T}=\left(\frac{L}{V_{r}}-\frac{L}{C} \cos \Theta\right)+\tau=\left(\frac{L}{V_{r}}+\tau\right)-\frac{L}{C} \cos \Theta
$$

In the above equation, the relationship between $T_{S P T}$ and $\cos \Theta$ is linear with a negative slope $-\frac{L}{C}$ and an intercept $\left(\frac{L}{V_{r}}+\tau\right)$. The relationship between $T_{S P T}$ and $\cos \Theta$ is a negative correlation for an unilateral faulting event. In general, $\left(\frac{L}{V_{r}}+\tau\right)$ is treated as the average source-process time (or whole source duration) observed at $\Theta=90^{\circ} \cdot \frac{L}{C}$ is

the propagation time needed for a surface wave to pass through the fault during the earthquake rupturing. We can link Eqs. (2) and (6) by a standard linear regression to estimate $\frac{L}{C}$ and $\left(\frac{L}{V_{r}}+\tau\right)$. The fault parameters, including the source-process time, rupture length, rupture velocity, and rupture azimuth, can then be determined.

Generally, it is easy to underestimate the value of the rupture velocity from the whole source duration $\left(\frac{L}{V_{r}}+\tau\right)$, including not only the rupture time $\frac{L}{V_{r}}$ but the rise time $(\tau)$. To correctly determine the rupture velocity from $\frac{L}{V_{r}}$, we use the period of the spectral node as obtained from the Fourier spectrum of the surface-wave to assist in isolating the rupture time $\frac{L}{V_{r}}$ from $\left(\frac{L}{V_{r}}+\tau\right)$. According to Eq. (4), the spectral nodes will appear in the Fourier spectrum when sin $X=0$ (i.e., $X=n \pi, n$ is the node number and $n=1,2,3, \ldots$ ) [please also refer to Chapter 14 of Aki and Richards (1980)]. These spectral nodes would arise at periods $T_{n}=\frac{1}{n}\left(\frac{L}{V_{r}}\right.$ $\left.\frac{L}{C} \cos \Theta\right)$, where the indices are the same as in Eq. (4). The relationship between the rupture directivity and the periods of the spectral nodes can now be written as follows:

$n T_{n}=\frac{L}{V_{r}}-\frac{L}{C} \cos \Theta$

The above equation is not inclusive of the rise time. A comparison of Eq. (6) with Eq. (7) shows them, in theory, to have the same slope. It is easy with Eq. (7) to detect the period of the first spectral node $(n=1)$. This is done by comparing them with the other nodes $(n=2,3, \ldots)$. The first node appears earliest in the long-period part of the Fourier spectrum. Hwang et al. (2001) successfully derived the rupture time of the $1999 \mathrm{M}_{\mathrm{w}}$ 7.6 Chi-Chi earthquake by using the period of the first spectral node of surface-wave. Of course, Eq. (7) can also be used to resolve the rupture directivity of large earthquakes. The fault parameters estimated using Eq. (7) however are relatively less stable than those made using Eq. (6), because it is more ambiguous to determine the period of the spectral node than to determine the difference in the phase-delay time of surface-waves between the main shock and reference earthquake. Hence, Eq. (6) is used primarily to estimate the fault parameters of the 2004 Sumatra earthquake.

Source rupture analysis reveals the complicated rupture pattern of the 2004 Sumatra earthquake (Ammon et al. 2005; Rhie et al. 2007). Multiple event analysis (Tsai et al. 2005) shows five sub-events with a moment magnitude $\left(\mathrm{M}_{\mathrm{w}}\right)$ of 8.54 - 9.00, distributed from north to south. Earthquakes of $\mathrm{M}_{\mathrm{w}} 8.54$ - 9.00 generally have source durations of less than $200 \mathrm{sec}$ (refer to the Harvard CMT and EIC of ERI earthquake catalogs). On the whole, the great 2004 Sumatra earthquake can be regarded more or less as an event with uniform rupturing in terms of surface-waves observations. For this reason, we use Eqs. (3) - (7) and the $100-200 \mathrm{sec}$ period phase-velocity for our study.

From Eqs. (4) and (5) it can be found that the source finiteness would result in the travel time delay of the surfacewave, related to $C$, a function of $\omega$. Strictly speaking, the source finiteness can be studied at a specified frequency. In other words, we can thus obtain the same fault parameters when using various frequencies of surface-wave. In fact, however, shallow structures (with stronger lateral variations than deep ones) will interfere with a short-period surfacewave. Hence, we use surface-waves with periods longer than $100 \mathrm{sec}$, which generally reflect structures about 200-km in depth or more. To reduce the effect of lateral structures, only the phase-delay times of surface-waves at periods of $140-160 \mathrm{sec}$ are adopted in our analysis. The final sourceduration is derived for each of the stations from the average of the differences between the phase-delay times of the main shock and reference earthquake waves at periods of 140 $160 \mathrm{sec}$ (Fig. 3). The distribution of the observed sourceduration at azimuths of $0^{\circ}-360^{\circ}$ (Fig. 3a) confirms the 2004 Sumatra earthquake to be a unilateral faulting event with obvious rupture directivity. A comparison shows that our results correspond well with those of Ni et al. (2005) obtained from high-frequency $P$-wave energy radiation. The source-process time and propagation time are estimated from Eq. (6) to be about $463.0 \mathrm{sec}$ (i.e., $\frac{L}{V_{r}}+\tau$ ) and $264.6 \mathrm{sec}$ (i.e., $\frac{L}{C}$ ) as shown in Fig. 3b. This is conditional on the misfit between the observed and predicted values reaching a minimum amount when an optimal rupture azimuth of $336^{\circ}$ 
(a)
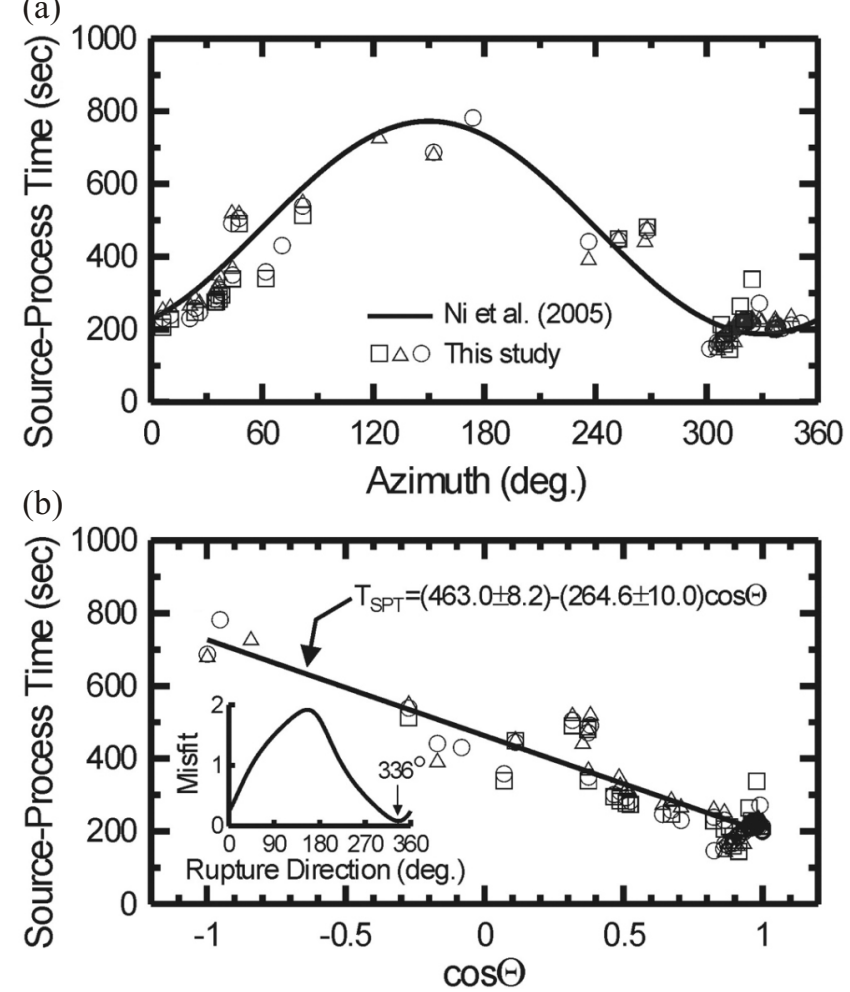

Fig. 3. (a) Estimated source-process times of the main shock observed at the available stations plotted against the station azimuth. The symbols denote the results for events 1,2 , and 4 . The line shows the estimation of the source-process time from $\mathrm{Ni}$ et al. (2005) for a rupture length of $1200 \mathrm{~km}$, a rupture azimuth of $330^{\circ}$ and a rupture velocity of $2.5 \mathrm{~km} \mathrm{sec}^{-1}$; (b) source-process time plotted against $\cos \Theta$. The rupture directivity analysis is performed by least-squares fitting with an optimal rupture azimuth. The inset denotes the optimal rupture azimuth $336^{\circ}$, determined from a minimum misfit.

is searched out. The misfit is defined as misfit $=1+\gamma$, where $\gamma$ is the correlation coefficient between the observed and predicted data. The estimated source-process time of $\sim 463.0 \mathrm{sec}$ is in good agreement with that obtained in other studies, 430 - $515 \mathrm{sec}$ (Guilbert et al. 2005; Ishii et al. 2005; Krüger and Ohrnberger 2005; Lomax 2005; Ni et al. 2005). The optimal rupture azimuth, $336^{\circ}$, measured clockwise from the north, approximates the strike of the fault plane solution as reported in the Harvard CMT cata$\log$. Figure $3 \mathrm{~b}$ shows that the apparent rupture velocity estimated from the whole source duration, approximately 2.5 $\mathrm{km} \mathrm{sec}^{-1}$, a value compatible with previous studies (Krüger and Ohrnberger 2005; Ni et al. 2005). However, with Eq. (6), the whole source duration, including the rise time and rupture time, will lead to an underestimation of the rupture velocity. In this study, we used the period of the spectral node of the Rayleigh-wave from the 2004 Sumatra earthquake to assist in determining the rupture time and the rise time (cf. Aki and Richards 1980; Hwang et al. 2001).
Owing to the long source duration (about 8-min) and the complexity of the rupturing of the 2004 Sumatra earthquake, it is difficult to determine the period of the first node from the Fourier spectrum. Hence, we must use a number of spectral node periods from the second or third nodes, especially for recordings from stations distant from the rupture direction. The results are shown in Fig. 3b. We can clearly see which station is far away from the rupture orientation of this earthquake. This is helpful to make a judgment about the spectral node. For example, we determine the first-node period $(n=1)$ from recordings at ABKT near to the rupture direction. Its first-node period is about $102.0 \mathrm{sec}$. The source duration observed at station ABKT is about $220.0 \mathrm{sec}$, so the rise time is estimated to be about $118.0 \mathrm{sec}$. If we suppose the node period at ABKT is not the first-node period (i.e., is the second node or more), the rise time will be merely $16 \mathrm{sec}$ or has a negative value, which is quite unreasonable for a large earthquake (cf. Geller 1976). As mentioned above, the rise time as derived from stations near to the rupture direction should be around $100 \mathrm{sec}$. The node number for a certain station away from the rupture direction can be determined from the difference between $n T_{n}$ [see Eq. (7)] and the observed source duration $\left(T_{S P T}^{o b s}\right)$. The difference must be around $100 \mathrm{sec}$. Figure 4a shows four node numbers at stations ABKT, MAJO, MIDW, and NWAO. To further estimate the rise time, we use the results shown in Fig. 3b, including the source duration $\left(\frac{L}{V_{r}}+\tau\right)$, propagation time $\frac{L}{C}$ and rupture azimuth $\left(\phi_{f}\right)$. The rise time can then be determined by searching for a series of given rise times $\left(\tau_{g}\right)$ at 0.1 sec intervals so as to minimize the difference $\left|n T_{n}-\left[\left(\frac{L}{V_{r}}+\tau\right)-\frac{L}{C} \cos \Theta\right]-\tau_{g}\right|$.

In Fig. $4 \mathrm{~b} n T_{n}$ [see Eq. (7)] is plotted with respect to $\cos \Theta$ after searching for the best rise time, $92.0 \mathrm{sec}$. The rupture time for the 2004 Sumatra earthquake is thus $371.0 \mathrm{sec}$, and the rupture velocity is estimated to be nearly $3.1 \mathrm{~km} \mathrm{sec}^{-1}$. This is higher than that determined in other studies (Guilbert et al. 2005; Ishii et al. 2005; Krüger and Ohrnberger 2005; Lomax 2005; Ni et al. 2005). However, multiple CMT source analysis (Tsai et al. 2005) implied an average rupture velocity of $\sim 3.0-3.1 \mathrm{~km} \mathrm{sec}^{-1}$ for the 2004 Sumatra earthquake. Discrepancies in the rupture velocity between our results and other studies might be due to the complexity of the earthquake. Our results obtain the first-order rupture feature (i.e., a uniform rupture) for the earthquake and also provide constraints for further source rupture analysis. The rise time of $92.0 \mathrm{sec}$ (i.e., the whole source duration subtracted from the rupture time) is about $20 \%$ of the source-process time ( $463.0 \mathrm{sec})$, which is consistent with observations for large earthquakes $(\geq 10 \%)$ (cf. Geller 1976). Taking the average phase velocity in the source area to be $4.4 \mathrm{~km} \mathrm{sec}^{-1}$, we estimate the rupture length from the propagation time to be about $1164-\mathrm{km}$. This value also coincides with the value 
obtained in previous studies $(1100-1300 \mathrm{~km})$ carried out according to a variety of data sets. The estimated fault parameters are summarized in Table 2.

\section{DISCUSSION AND CONCLUSIONS}

Several basic fault parameters (Table 2) for the 2004 Sumatra earthquake are estimated through rupture directivity analysis. This is done by observing source-duration variations from the station azimuth [based on the work of Hwang et al. (2001)]. We derive a long source-process time $(\sim 463.0 \mathrm{sec})$ and large rupture $(\sim 1164-\mathrm{km}-\mathrm{long})$. These values are in good agreement with previous studies. The rupture length and source-process time for the 2004 Sumatra earthquake are larger than those for the 1960 Chile earthquake $(\sim 1000 \mathrm{~km})$ and the 1964 Alaska earthquake $(\sim 650 \mathrm{~km})(\mathrm{cf}$. Press et al. 1961; Ben-Menahem et al. 1972; Furumoto and Nakanishi 1983). The average rupture velocity $\left(3.1 \mathrm{~km} \mathrm{sec}^{-1}\right.$, $\sim 0.83 \mathrm{~V}_{\mathrm{S}}$ at $\mathrm{V}_{\mathrm{S}}=3.75 \mathrm{~km} \mathrm{sec}^{-1}$ ) determined only by the rupture time is obviously higher than that $\left(2.5 \mathrm{~km} \mathrm{sec}^{-1}, \sim 0.67 \mathrm{~V}_{\mathrm{S}}\right.$ at $\mathrm{V}_{\mathrm{S}}=3.75 \mathrm{~km} \mathrm{sec}^{-1}$ ) determined by the whole source duration. The former seems consistent with the results from multiple event analysis (Tsai et al. 2005) and the latter is in agreement with previous studies from hydroacoustic data and regional seismic network (Guilbert et al. 2005; Ishii et al. 2005; Krüger and Ohrnberger 2005; Lomax 2005; Ni et al. 2005). Also, the estimated rupture length (1164-km) agrees well with a result derived from high-frequency $P$-wave energy radiation ( $\mathrm{Ni}$ et al. 2005). At any rate, the rupture velocity for the 2004 Sumatra earthquake (see Table 2) is larger than that for the so-called "tsunami earthquake", which is characterized by a slow rupture velocity and slow slip velocity or low ratio $\left(E_{s} / M_{0}\right)$ of radiated energy $\left(E_{s}\right)$ to the seismic moment $\left(\mathrm{M}_{0}\right)$ (Kanamori 1972; Polet and Kanamori 2000). Kanamori (2006) estimated the $\mathrm{E}_{\mathrm{s}} / \mathrm{M}_{0}$ for the 2004 Sumatra earthquake to be $4.6 \times 10^{-6}$. It displays characteristics of subduction zone earthquakes but not tsunami earthquakes. However, Seno and Hirata (2007) suggested that the 2004 Sumatra earthquake likely had a component characteristic of tsunami earthquakes. They utilized a rupture model with a rapid rupture velocity of $\sim 2.5 \mathrm{~km} \mathrm{sec}^{-1}$ at the depth relative to a slow rupture velocity of $\sim 0.7 \mathrm{~km} \mathrm{sec}^{-1}$ at shallow depths. Our results seem to reflect the rupture at the depth where the main ruptures occurred (Ammon et al. 2005; Rhie et al. 2007). We obtain a higher rupture velocity from surface-wave estimation which might account for the main rupturing process, and imply a relatively low fracture energy and high radiation efficiency.

The estimated rise time $(92.0 \mathrm{sec})$ for the 2004 Sumatra earthquake is approximately $20 \%$ of the whole source duration, larger than either the 1960 Chile earthquake or the 1964 Alaska earthquake, which was predicted to be $\sim 35 \mathrm{sec}$ (cf. Geller 1976). This probably reflects a fundamental difference in the frictional properties of the earthquake faulting.
The rise time obtained in this study is comparable to that $(90 \mathrm{sec})$ of Seno and Hirata (2007). The estimated rupture azimuth also fits the features of the plate tectonics in the source area and the Harvard CMT solution. We also compare our results with the fault parameters of several great historical earthquakes. Figure 5 shows the source-process times vs.
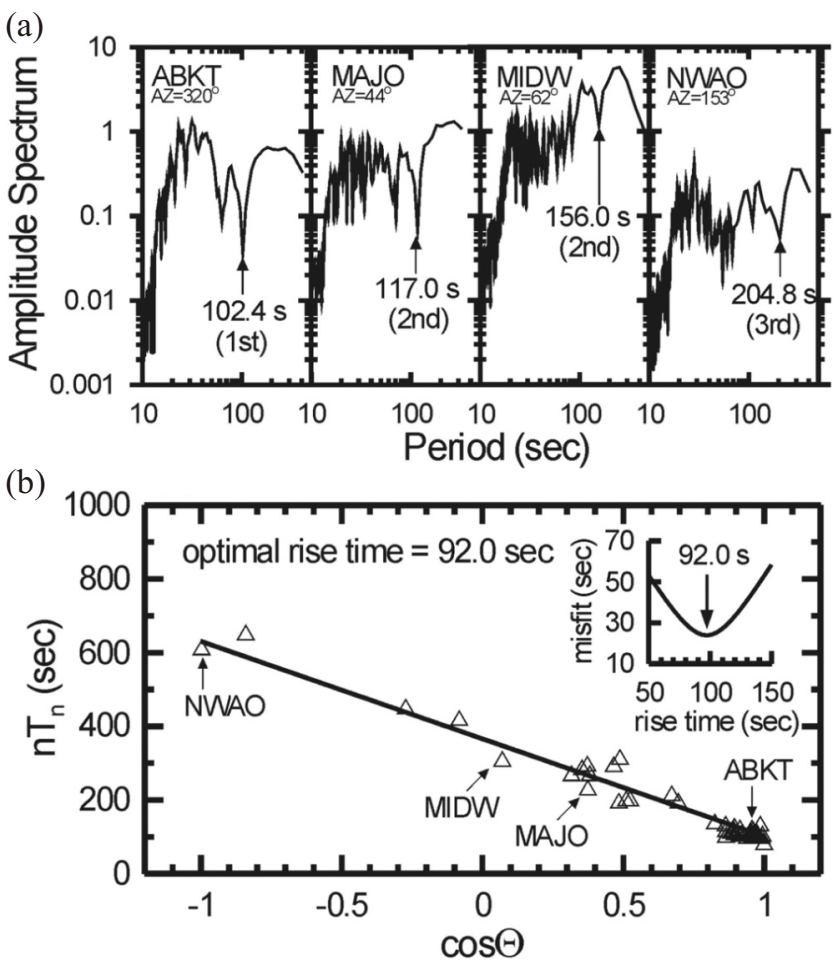

Fig. 4. (a) Examples of amplitude spectra for stations MAJO, ABKT, NWAO $\left(32.9266^{\circ} \mathrm{S}\right.$ and $\left.17.2333^{\circ} \mathrm{E}\right)$, and MIDW $\left(28.2157^{\circ} \mathrm{N}\right.$ and $177.3697^{\circ} \mathrm{W}$ ) at periods of $10-400 \mathrm{sec}$. The arrows designate the position of the spectral nodes and their corresponding periods; node numbers are also shown below; (b) The plot of $n T_{n}$ [see Eq. (7)] where $\cos \Theta$ indicates the optimal estimation of rise time obtained through a grid search. The solid line is derived from the equation: $371.0-264.6 \cos \Theta$.

Table 2. Fault parameters estimated in this study.

\begin{tabular}{ll}
\hline Rupture length of earthquake fault & $1164.2 \pm 44.0 \mathrm{~km}$ \\
Average source-process time & $463.0 \pm 8.2 \mathrm{sec}$ \\
Rupture azimuth & $336^{\circ}$ \\
Rupture time & $371.0 \pm 8.2 \mathrm{sec}$ \\
Rise time $^{1}$ & $92.0 \mathrm{sec}$ \\
Rupture velocity $^{2}$ & $2.5 \pm 0.1 \mathrm{~km} \mathrm{sec}^{-1}$ \\
Rupture velocity $^{3}$ & $3.1 \pm 0.1 \mathrm{~km} \mathrm{sec}^{-1}$ \\
\hline
\end{tabular}

${ }^{I}$ The rise time is determined through a grid search based on rupture directivity analysis done from phase-delay times of surface waves.

${ }^{2}$ The rupture velocity is estimated from the whole source duration.

${ }^{3}$ The rupture velocity is estimated only from the rupture time. 
seismic moments for several large earthquakes and our study. The solid line indicates a plot of the results obtained from an empirical formula derived by Furumoto and Nakanishi (1983). The seismic moment of the 2004 Sumatra earthquake $\left(1.0 \times 10^{30}\right.$ dyne-cm) was estimated by Stein and Okal (2005). The estimated source-process time for the 2004 Sumatra earthquake is not only larger than that $(\sim 343.0 \mathrm{sec})$ predicted by this empirical formula, but also larger than that for the 1960 Chile $(\sim 390 \mathrm{sec})$ and 1964 Alaska earthquakes ( $400 \mathrm{sec}$ ) (cf. Furumoto and Nakanishi 1983). This might be due to the longer rupturing during the 2004 Sumatra earthquake faulting. In terms of their magnitudes, the two historical earthquakes should be reexamined by our proposed method. In this study, the approach to estimating the source duration is basically similar to the deconvolution of $P$-waves or surface-waves (cf. Schwartz and Ruff 1985; Ammon et al. 2005). Although we cannot derive the complexity of the earthquake rupturing as can be done by the deconvolution of $P$-waves or surface-waves, we find our determination of the variation of the source duration with the azimuth from the phase-delay time difference to be relatively more stable than that determined from the Relative Source Time Function (RSTF). The stable source-duration estimation [through Eq. (6)] makes the rupture directivity analysis more reasonable. For this reason, we can make relatively accurate estimates of the fault parameters which represent the first-order rupturing feature of the 2004 Sumatra earthquake. The rupture length, exceeding $1100-\mathrm{km}$, is estimated from the propagation time [i.e., $\frac{L}{C}$ in Eq. (6) and

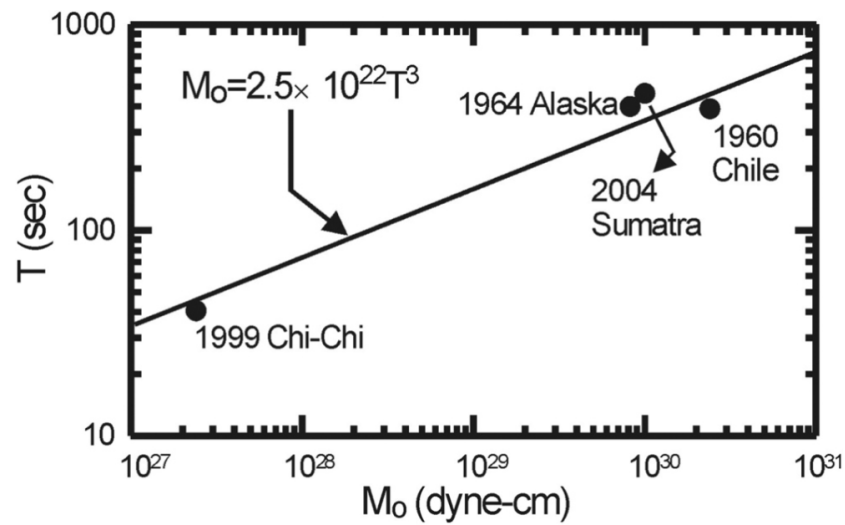

Fig. 5. Comparison of the seismic moment $\left(M_{0}\right)$ to the source-process time $(\mathrm{T})$ for several large earthquakes. The line indicates the theoretical values calculated by: $M_{0}=2.5 \times 10^{22} T^{3}$ (Furumoto and Nakanishi 1983). The source-process time and seismic moment for the 1960 Chile and the 1964 Alaska earthquakes are taken from Furumoto and Nakanishi (1983); the source-process time of the 1999 Chi-Chi earthquake comes from Hwang et al. (2001) and its seismic moments come from the Harvard CMT catalog. The source-process time of the 2004 Sumatra earthquake comes from this study and its seismic moments are taken from Stein and Okal (2005)
Fig. 3b], in connection with $C$ (phase velocity in the source area). In spite of the relatively lower source duration $(<8 \mathrm{~min})$, the results represent the main energy release during the 2004 Sumatra earthquake. In addition, it has not been possible in previous studies to derive the rise time, which is related to the dynamic stress drop during the earthquake faulting. However, with our proposed method for data processing, the rise time is evaluated, and then used to determine the average slip velocity (in case where the average dislocation is known). Since the whole source duration and rise time are obtained, the rupture time can be estimated accurately. This will lead to a reasonable estimation of rupture velocity. The ignoring of the rise time in previous studies has resulted in underestimation of the rupture velocity. It might be feasible to use the method discussed in this study to reexamine and obtain more systematic estimations of the fault parameters for historical or recent earthquakes, and then to determine a new scaling relationship between these fault parameters.

Acknowledgements The authors would like to express their gratitude to IRIS for providing us with the GSN data. We also offer special thanks to Dr. Li Zhao and the anonymous reviewer for their critiques which have helped us to greatly improve the manuscript. This study was financially supported by the National Science Council, ROC, under Grant No. NSC97-2116-M-034-002.

\section{REFERENCES}

Aki, K. and P. G. Richards, 1980: Quantitative Seismology: Theory and Methods, W. H. Freeman, San Francisco, 932 pp.

Ammon, C. J., J. Chen, H. K. Thio, D. Robinson, S. Ni, V. Hjorleifsdottir, H. Kanamori, T. Lay, S. Das, D. Helmberger, G. Ichinose, J. Polet, and D. Wald, 2005: Rupture Process of the 2004 Sumatra-Andaman Earthquake. Science, 308, 1133-1139, doi: 10.1126/science.1112260. [Link]

Ben-Menahem, A., 1961: Radiation of seismic surface-waves from finite moving sources. Bull. Seismol. Soc. Am., 51, 401-435.

Ben-Menahem, A., M. Rosenman, and M. Israel, 1972: Source mechanism of the Alaskan earthquake of 1964 from amplitude of free oscillations and surface waves. Phys. Earth Planet. Inter., 5, 1-29, doi: 10.1016/0031-9201(72)90071-4. [Link]

Chang, W. Y., G. K. Yu, R. D. Hwang, and J. K. Chiu, 2007: Lateral variations of Rayleigh-wave dispersions in the Philippine Sea region. Terr. Atmos. Ocean. Sci., 18, 859878, doi: 10.3319/TAO.2007.18.5.859(T). [Link]

de Groot-Hedlin, C. D., 2005: Estimation of the rupture length and velocity of the Great Sumatra earthquake of Dec 26, 2004 using hydroacoustic signals. Geophys. Res. Lett., 32, L11303, doi: 10.1029/2005GL022695. [Link]

Furumoto, M. and I. Nakanishi, 1983: Source times and scaling relations of large earthquakes. J. Geophys. Res., 88, 2191- 
2198, doi: 10.1029/JB088iB03p02191. [Link]

Geller, R. J., 1976: Scaling relations for earthquake source parameters and magnitudes. Bull. Seismol. Soc. Am., 66, 1501-1523.

Guilbert, J., J. Vergoz, E. Schisselé, A. Roueff, and Y. Cansi, 2005: Use of hydroacoustic and seismic arrays to observe rupture propagation and source extent of the $M_{w}=9.0 \mathrm{Su}-$ matra earthquake. Geophys. Res. Lett., 32, L15310, doi: 10.1029/2005GL022966. [Link]

Hwang, R. D., 1999: Upper Mantle structure of the mainland China from surface wave dispersion data. Ph.D. Dissertation, National Central University, Chung-Li, Taiwan, $135 \mathrm{pp}$.

Hwang, R. D., G. K. Yu, and J. H. Wang, 2001: Rupture directivity and source-process time of the September 20, 1999 Chi-Chi, Taiwan, earthquake estimated from Rayleigh-wave phase velocity. Earth Planets Space, 53, 11711176.

Ishii, M., P. M. Shearer, H. Houston, and J. E. Vidale, 2005: Extent, duration and speed of the 2004 Sumatra-Andaman earthquake imaged by the Hi-Net array. Nature, 435, 933936, doi: 10.1038/nature03675. [Link]

Kanamori, H., 1972: Mechanism of tsunami earthquakes. Phys. Earth Planet. Inter., 6, 346-359, doi: 10.1016/0031-9201 (72)90058-1. [Link]

Kanamori, H., 2006: The radiated energy of the 2004 SumatraAndaman earthquake. In: Radiated Energy and the Physics of Earthquake Faulting, Geophysical Monograph Series 170, American Geophysical Union, Washington DC, 5968.

Krüger, F. and M. Ohrnberger, 2005: Tracking the rupture of the $M_{\mathrm{w}}=9.3$ Sumatra earthquake over $1,150 \mathrm{~km}$ at teleseismic distance. Nature, 435, 937-939, doi: 10.1038/nature03696. [Link

Lay, T., H. Kanamori, C. J. Ammon, M. Nettles, S. N. Ward, R. C. Aster, S. L. Beck, S. L. Bilek, M. R. Brudzinski, R. Butler, H. R. DeShon, G. Ekström, K. Satake, and S. Sipkin, 2005: The Great Sumatra-Andaman Earthquake of 26 December 2004. Science, 308, 1127-1133, doi: 10.1126/science.1112250. [Link]

Lomax, A., 2005: Rapid estimation of rupture extent for large earthquakes: Application to the 2004, M9 Sumatra-Andaman mega-thrust. Geophys. Res. Lett., 32, L10314, doi: 10.1029/2005GL022437. [Link]

Ni, S., H. Kanamori, and D. Helmberger, 2005: Seismology: Energy radiation from the Sumatra earthquake. Nature,
434, 582, doi: 10.1038/434582a. [Link]

Polet, J. and H. Kanamori, 2000: Shallow subduction zone earthquakes and their tsunamigenic potential. Geophys. J. Int., 142, 684-702, doi: 10.1046/j.1365-246x.2000. 00205.x. [Link]

Press, F., A. Ben-Menahem, and M. N. Toksöz, 1961: Experimental determination of earthquake fault length and rupture velocity. J. Geophys. Res., 66, 3471-3485, doi: 10.1029/JZ066i010p03471. [Link]

Rhie, J., D. Dreger, R. Bürgmann, and B. Romanowicz, 2007: Slip of the 2004 Sumatra-Andaman earthquake from joint inversion of long-period global seismic waveforms and GPS static offsets. Bull. Seismol. Soc. Am., 97, S115-S127, doi: 10.1785/0120050620. [Link]

Schwartz, S. Y. and L. J. Ruff, 1985: The 1968 Tokachi-Oki and the 1969 Kurile Islands earthquakes: Variability in the rupture process. J. Geophys. Res., 90, 8613-8626, doi: 10.1029/JB090iB10p08613. [Link]

Seno, T. and K. Hirata, 2007: Did the 2004 Sumatra-Andaman earthquake involve a component of tsunami earthquakes? Bull. Seismol. Soc. Am., 97, S296-S306, doi: 10.1785/ 0120050615. [Link]

Stein, S. and E. A. Okal, 2005: Seismology: Speed and size of the Sumatra earthquake. Nature, 434, 581-582, doi: 10.1038/ 434581a. [Link]

Tsai, V. C., M. Nettles, G. Ekström, and A. M. Dziewonski, 2005: Multiple CMT source analysis of the 2004 Sumatra earthquake. Geophys. Res. Lett., 32, L17304, doi: 10.1029/ 2005GL023813. [Link]

Vigny, C., W. J. F. Simons, S. Abu, R. Bamphenyu, C. Satirapod, N. Choosakul, C. Subarya, A. Socquet, K. Omar, H. Z. Abidin, and B. A. C. Ambrosius, 2005: Insight into the 2004 Sumatra-Andaman earthquake from GPS measurements in southeast Asia. Nature, 436, 201-206, doi: 10.1038/ nature03937. [Link]

Wang, C. Y., 1981: Wave theory for seismogram synthesis. Ph.D. Dissertation, Saint Louis University, Saint Louis, 235 pp.

Yagi, Y., 2005: Preliminary Results of Rupture Process for 2004 off coast of Northern Sumatra giant earthqauke, posted on http://iisee.kenken.go.jp/staff/yagi/eq/Sumatra2004/Suma tra2004.html.

Yamanaka, Y., 2005: EIC Seismological Note No. 161+: Off the West Coast of Northern Sumatra Earthquake (M9.0), posted on http://www.eri.u-tokyo.ac.jp/sanchu/Seismo Note/2004/EIC161ea.html. 